Kitap, Tez, Sempozyum Değerlendirmeleri

\title{
Vincent Mansour Monteil Vefat Etti ${ }^{1}$
}

AHMET KAVAS

DOC. DR., ISAM

27 Mayıs 1913 tarihinde Fransa'nın Corèzze şehrinde doğan Vincent Monteil'in babası Charles Monteil Fransız sömürgeciliğinin zirvede olduğu XX. yüzyılın başında Batı Afrika'da vergi tahsildarı olarak görev yapıyordu. $O$ yıllarda subay olan amcası Parfait Louis Monteil (ö1925) de Afrika kutasına, özellikle de Müslüman toplumlara büyük bir hayranlık duyuyordu. Hatta kendisinden önce Afrika'yı dolaşan seyyahlardan farklı olarak bir ilki gerçekleştirmiş ve bugünkü Senegal devletinin Atlas Okyanusu sahilindeki Saint-Louis şehrinden 1890 yllında deve sırtında hareket edip Nijer nehri boyunca içerilere doğru giderek Çad Gölü'ne kadar ilerlemiş, buradan da kuzeye doğru yolculuğunu sürdürüp bugünkü Libya'nın başkenti Trablusgarp'a 1892 yılında sağ salim ulaşma başarısını göstermişti. Bu seyahatini daha sonra De Saint-Louis à Tripoli par le lac Tchad. Voyage au travers du Soudan et du Sahara accompli pendant les années 1890-91-92 adıyla kitaplaştırmıştı. Charles Monteil de abisinden geri durmadı ve Afrika'nın tarihi, etnografyası, antropolojisi, dinî hayatı ve yerli dilleri hakkında araştırmalar yaptı ve bu alanlarda kitaplar ile çok sayıda makale telif etti. Bugünkü Mali Cumhuriyeti'nin tarihi şehirlerinden Cenne (Djenné) hakkında Une cité soudanaise: Djenné. Métropole du Delta central du Niger adıyla yazdığ eser alanında ilk önemli kaynaktır. Böylesine Afrika meraklısı bir aileye sahip genç Vincent de ilerideki hayatını şekillendirecek eğitimi konusundaki ilk tercihini amcası gibi askerlik mesleğine yönelerek belirledi ve Paris'teki Saint-Cyr askeri okuluna kayıt yaptırdı.

1 Geniş bilgi için bakınız: Ahmet KAVAS, "Şarkiyatçılığı Askerliğe Tercih Eden Fransız Mühtedi: Vincent-Mansour Monteil (Mütercim, Seyyah, Islâm Dünyası ve Afrika Uzmanı)", Oryantalistlerin Gözüyle İslâm Yaklaşımlar-Örnek Metinler, (ed. Ahmet Yücel), Rağbet Yayınları-Yeni Arayışlar Platformu Kitapları, n.6. İstanbul 2002, s.333-375. 
Sömürgeciliğin en etkili olduğu dönemlerde İngilizler'in bir kahraman olarak takdim ettikleri Lawrence Avrupalı gençliğin hayalinde örnek bir şahsiyet haline geldiği için onun 1935'te erken ölümü Vincent'i de üzdü. Çünkü pek çok genç subay adayı gibi o da bir Lawrence hayranıydı. Tam 50 sene onun hakkında gördüğü her kitabı ve makaleyi, gazete yazısını büyük bir itina ile topladı ve sonunda Lawrence d'Arabie. Le lévrier fatal 18881935 adıyla kitaplaştırdı. Ancak o bu eserinde artık ne bir Lawrence hayranıydı, ne de onu bilmeden körü körüne eleştirenlerdendi, sadece İngilizler'in bu abartılı kahramanını gerçek kimliğiyle tahlil etti.

Charles Monteil 1938 yılında oğlunu devrin büyük şarkiyatçısı Louis Massignon ile tanıştırdı. Bu tanışıklık onun hayatında yeni bir kapıyı arala$\mathrm{d}_{1}$ ve genç Monteil yavaş yavaş Ortadoğu ve İslâm dünyasına ilgi duymaya başladı, Arapça öğrendi. 1940 yllında ilk görev yeri olan ve o dönemde himaye adı altında Fransa tarafından sömürülen bugünkü Fas devletine askeri görevle gönderildi. Ancak onun Fas'taki bazı tavırları Fransa'da İkinci Dünya Savaşı sırasında kurulan ve 1940-1944 yılları arasında iktidarı elinde bulunduran Vichy hükümetinin hoşuna gitmedi ve tutuklanarak hapse konduysa da bir müddet sonra çıkarıldı. Her subay gibi o da kendini Almanlara karşı verilen amansız savaş sırasında cephelerde buldu. Bir kez de cephedeyken aynı hükümet tarafından tutuklanıp hapse atıldı ve ileride Fransa başbakanı olacak Pierre Mendes France ile aynı hücrede yattı. Yeniden serbest bırakılmasının ardından tekrar cepheye döndü ve savaşın sonlarına doğru bindiği askeri cipe Almanların attı̆̆ı bir top parçası isabet edince ağır yaralandı. Assl görev yeri olan Fas'a ancak 1948 yılında dönebildi. Fakat bu görevinde fazla kalmaya niyetli değildi ve aynı yıl içerisinde Paris'e gelerek Kuzey Afrika Kara-Deniz ve Hava Kuvvetleri Komutanhı̆̆ında görev aldı. Bu işine fazla devam edemeden Italya'dan bağımsızlığını yeni alan Libya krallığına askeri ateşe olarak tayin edildi. İsrail ile Araplar arasında 1948 'te çıkan savaş alanına Birleşmiş Milletler tarafından gönderilen barış heyetinin içerisinde yer aldı. Daha o dönemde İsraillilerin yanlış yaptıklarını her yerde söylemeye başladı ve orada yaşadıklarını Soldat de Fortune adlı eserinin ilk bölümü olan "Entre les lignes" başhlkhı kusımda teferruatlı olarak anlattı (s. 23-62).

Dünyada yeni düzenlerin kurulmaya başladığı İkinci Dünya Savaşı sonrasında askeri kimliğine rağmen Vincent Monteil hocası kabul ettiği Louis Massignon gibi sömürgeciliğe karşı bir tavir sergiledi. Tunus ve Cezayir'in bağımsızlıkları için mücadele edenlerin önderlerine karşı ülkesinin sömürge idarecilerinin sert tavırlarına daima karşı geldi. Bu amaçla Paris'te zaman zaman kendisi gibi düşünenlerle toplantılar yaptı ve buraya Louis 
Massignon ile Fransız şarkiyatçılı̆̆ının önde gelen bir diğer ismi olan Jacques Berque de katılmaktaydı. İçine girdiği bu şarkiyatçılar çevresi Vincent Monteil'i yavaş yavaş askerlik mesleğinden soğuttu.

Paris'teki Doğu Dilleri Enstitütüsü'nde bir müddet Farsça derslerini takip eden Vincent Monteil 1950-1952 yılları arasında İran'a askeri ateşe olarak tayin edildi. Burada Farsça bilgisini daha da geliştirdi ve o yıllarda büyük bir dostluk kurduğu İranlıların meşhur yazarlarından Sadık Hidayet'in iki küçük kitabını Fransızcaya tercüme etti. Ayrıca o günlerde yazdığı Iran adlı eseri sebebiyle Şah'ın istihbarat örgütü SAVAK tarafından bu ülkeye girişi yasaklandı ve Humeyni'nin iktidarı ele geçirişine kadar bu yasak devam etti.

Sağlığı elvermediği için çok istediği halde Vincent Monteil Vietnam Savaşı'na katılamadı, ama 1953 yılı içerisinde henüz devam eden Kore Savaş’na Birleşmiş Milletlerin gönderdiği Fransız Takviye Birlikleri'nin komutanı olarak gitti. Orada bulunduğu sırada Hollanda'nın getirdiği sömürge askerlerinden Malay dilini öğrendi. Komutanlığını yaptığı birlik doğrudan Fransa'ya dönmeyip bir müddet Vietnam'da görevlendirilince böylece ülkesinin bu sömürgesinde de kalma fırsatı buldu.

İkinci Dünya Savaşı sırasında birlikte hapishanede yattığı Pierre Mendès France 1954 yılında başbakan olunca onun kurduğu hükümette FasTunus İşleri Bakanı olan Christian Fourchet tarafından Vietnam'daki görevinden çağnıldı ve bu bakanlıkta görev aldı. Bizzat başbakanın da desteğine güvenerek Kuzey Afrika'ya gidip bu bölgedeki bağımsızlık hareketlerini yönlendiren mahkûmları tutuldukları hapishanelerde ziyaret etti. 1955 yılında Fransa'nın Tunus ile yaptığı anlaşmanın imzalanmasında önemli rol oynadı. Aynı yıl Cezayir'deki Fransız Askeri Birliği Özel Kalem Müdürlüğüne tayin edilince bütün vaktini tekrar hapishaneleri gezmeye ayırdı ve haksız yere tutuklanan Cezayirli önde gelenlerin serbest bırakılmalarıyla meşgul oldu. Ancak onun serbest bıraktırdığı kişiler Fransız basının yönlendirmesiyle birkaç gün sonra sömürge idaresince tekrar tutuklanmaktaydı, hatta içlerinden bir kısmı idam edildi. Bu durum karşısında sömürge valisi Jean Soustelle ile tartışan Vincent Monteil gayretlerinin boşa gittiğini görünce bu görevinden istifa edip Paris'teki görevine döndü. 1956 yllında gönderildiği Fas'ta da Cezayir'dekine benzeyen tecrübeleri aynen yaşadı. Bütün bunlardan sonra halen sömürgecilikte ssrar eden ülkesinin bir askeri olarak bu görevde daha fazla kalmak istemiyordu.

Fransız Dışişleri Bakanlığı Lübnan'ın Bikfaya şehrinde Uygulamalı Modern Arapça Merkezi Müdürlüğü açmış ve başına Vincent Monteil'in de çok değer verdiği şarkiyatçı Jacques Berque getirilmişti. Onun Fransızların en 
itibarlı bilim kuruluşlarından birisi olan Collège de France'a üye seçilince Paris'e dönmesi üzerine 1956 yılında bu merkezin müdürlüğü Vincent Monteil'e teklif edildi ve iki aylık bir düşünmenin ardından bu göreve gitti ve 1959 yılına kadar Lübnan'da kalarak Arapçası'nı geliştirdi. O yıllarda henüz kimsenin pek ilgilenmediği Sovyetler Birliği'nde yaşayan Müslümanlar üzerine Les musulmans sovietiques (Paris 1957) isimli kitabını yazdı ve dönemin Fransa devlet başkanı Charles de Gaule bu çalışmasından dolayı kendisini yazll olarak tebrik etti.

1960 yılında hem bu görevine, hem de bir daha dönememek üzere askerlik görevine veda etti. Bu arada modern Arapça üzerine hazırladığı doktora tezini de aym yıl Sorbonne Üniversitesi'nde savundu ve bu çalışmasını L'Arabe moderne adıyla kitaplaştırdı.

Vincent Monteil artık bütün vaktini ilmi araştırmaya verdi ve özellikle Afrika'yı kendisine sevdiren babasının yolundan giderek Senegal'e gitti. Burada 1959-1968 yılları arasında yaklaşık on sene kaldı ve bugünkü adıyla Cheikh Anta Diop Üniversitesi'nin Edebiyat ve İnsan Bilimleri Fakültesi'ndeki Arap Dili bölümü ile İslâm Enstitüsü'nde ders verdi. Yine sömürge döneminde ülkesinin kurduğu Fransız Siyah Afrika Enstitüsü (Institut Français de l'Afrique Noire) müdürü Théodore Monod'un yerine geçti. Batı Afrika Müslümanlarına ait kuymetli el yazmalarını toplayarak ciddi bir yazma koleksiyonu oluşturdu. Senegal'de bulunduğu 1964'te Amerika Birleşik Devletleri'ne gitti ve orada yaşayan zenci Müslümanlar üzerine "Siyah Müslümanlar'ın Dini/La religion des Blacks Muslims" başlıklı bir makale yazdı. Yine o yıllarda Siyah Afrika Müslümanları üzerine telif ettiği L'Islam noir (Paris 1964) isimli eserini kendisine Afrika'yı sevmeyi öğreten babası Charles Monteil'e ithaf etti. İzzet Tanju tarafindan Afrika'da İslâm (Pınar Yayınları, İstanbul 1992) adıyla Türkçe'ye tercüme edildi. Monteil'in Paris7 Üniversitesi'ndeki haleflerinden olan Jean-Louis Triaud'a göre bu eser Fransızcada Siyah Afrika'daki İslâm üzerine yapılan araştırmalar için önemli bir dönüm noktasıdır.

Senegal'den ayrıldıktan sonra bu defa İslâm dünyasının en doğusundaki Endonezya'ya gitti ve 1969-1971 yılları arasında buranın başkenti Cakarta'daki Fransız büyükelçiliği nezdinde kültür müşavirliği görevini yürüttü. Orada bulunduğu yıllarda Endonezya üzerine Indonésie isimli kitabını telif edip bastırd.

Endonezya dönüşü eski adı Paris-7 Üniversitesi olan ve bugünkü adıyla Denis Diderot Üniversitesi'nin Arap Medeniyeti ve İslâm Kültürü bölümünde ders vermeye başladı. Kendisi bu görevi bırakınca yerine yine İslâm dünyası konusunda yetişmiş bir ilim adamı olan Necmeddin Bammat geçti. 
Vincetn Monteil 1970'li yillarda Arnavutluk, Birmanya, Japonya ve İrlanda'ya seyahatlerde bulundu. 1977 yllında Moritanya'nın başkenti Nuakşot'ta Müslüman olduğunu ilan etti ve Mansur (Mansour) ismini aldı. Kendisine neden bu ismi aldığını soranlara bunun asıl ismi olan Vincent'in Arapça karşllığı olduğunu söylüyordu. Endonezya'da bulunduğu yıllarda yakından tanıdığı bu ülke Müslümanları'nın dinî hayatından çok etkilendiği için de mezhep olarak Şafîiliği seçti.

Vincent Mansour Monteil 6 Ocak 1990 tarihli bir yazısında Fransa'da basının her gün İslâm'ın aleyhinde yazılar yayımlamasından rahatsızlık duyduğunu, bu dine karşı yapılan saldırılara cevap vermek istediğini, ancak bu konuda kendisine imkân verilmediğini ifade etmekteydi. Öyleki hiçbir devlet televizyonu, resmi ve özel radyolar İslâm konusunda ilgili ilgisiz herkesin görüşüne yer verirken onu tamamen dışlamaktaydılar. Bunun sebebi ise İsrail'in teröre bulaştığını anlattığı kitabı Dossier secret sur Israél: le Terrorisme (İsrail Hakkında Gizli Dosya: Terör, (trc.: Ergün Göze, Boğaziçi Yayınları, İstanbul 1995) sebebiyle gazeteleriyle, televizyonlarıla ve radyolarıyla bütün medya kendisini yok kabul ediyordu.

Emekliye ayrıldıktan sonra Paris'in merkezinde bulunan iki odalı evinde yalnız başına münzevi bir hayat yaşamaya başladı. Tek başına sürdürdüğü hayatını tamamen ilme adadı ve daha önce tamamladığı eserlerinden başka çok sayıda yeni telif ve tercüme kitap ile ilmi makale kaleme aldı. Arapça, Farsça, Türkçe ve Malayca gibi İslâm dünyasında en yaygın konuşulan dilleri gayet iyi bilen Monteil Almanca, İngilizce, İtalyanca gibi önde gelen Avrupa dillerine de çok iyi derecede vakıftı.

Evinin duvarları içleri birbirinden kıymetli tarihi kitaplarla dolu raflarla kaplıydı ve bunların önündeki fotoğraflar içinde dördü büyük ebatlarıyla diğerlerinden hemen ayırt ediliyordu. Özellikle Fransa'nın efsanevi devlet adamı ve komutanlarından Charles de Gaule, Fransızlar'ın en büyük şarkiyatçllarından Louis Massignon, 1973 yılında Paris'te tanıştığı ve 1981'de de Trablusgarp'da tekrar görüştüğü Muammer Kaddafi ve 1979 yllında Paris'te sürgündeyken ziyaret ettiği İran devrimini gerçekleştiren İmam Humeyni'ye ait fotoğraflar adeta her gün onunla sohbet ediyor gibi çalışma odasındaki masasının yanı başında duruyorlardı. Hayatında bu dört şahsiyetin hep ayrı bir yeri olduğu kendi ifadelerinden de anlaşılıyordu.

Vincent Monteil'in en büyük emek sarf ederek ortaya koyduğu eser hiç şüphesiz Fransızca'ya tercüme ettiği İbn Haldun'un Mukaddimesi'dir. Önce Türkiye'deki kütüphanelerde mevcut yazmalardan hareketle tenkitli bir metin hazırlayan Monteil'in bu kıymetli eseri Fas kralı tarafından sınırlı sayıda basıldı. Ardından bu son derece kıymetli Arapça metni tam altı yıl 
başka hiçbir çalışmayla meşgul olmadan Fransızcaya tercüme etti ve halen Fransa'da piyasada bulunan Mukaddime tercümesi ona ait olup ilk defa 1967'de Beyrut'ta basılan eser, en son 1997 ynlındaki Paris baskısına kadar, defalarca yayımlandı (Discours sur l'histoire universelle d'Ibn Khaldûn).

İslâm dünyası hakkında genel bilgi verdiği Le monde musulman isimli eserinde farklı soylardan Müslüman portreleri ve mimari şaheserlerin fotoğraflarıla süslü son derece önemli bir eseri bulunmaktadır. Arap dünyasını anlatmak için kaleme aldığı Le monde arabe isimli eserinde Müslümanların bilime katkılarını göstermek için kymetli minyatür desenlerini koymayı tercih etti. Arapların meşhur âmâ şairi Ebu'l-Ala el-Maarrî, Ebû Nüvâs, Ömer Hayyam, Hâfız, el-Birûnî, İbn Haldûn, Yunus Emre gibi her biri sahalarında zirveye çıkmış ilim ve gönül adamlarının eserlerini Vincent Mansour Monteil bir sarraf hassasiyeti ile yakından inceleyip bunlar üzerine eserler ortaya koydu. Hatta XX. yüzyılda yaşayan İranlı şair Sadık Hidayet gibi yeni isimler de onun ilgi alanına girebilmekteydi. Yine XX. yüzyllda İslâm dünyasının geleceğini karartmak için entrikalar çeviren ve bunda da belli bir seviyede başarılı olan Lawrence'i bir kitap çerçevesinde incelemeden edemedi. Hayatının en az 60 yılını İslâm dünyasını ve bu dine inananların insanlık tarihine yaptıkları büyük katkıları anlatmak için geçirerek 40 kadar telif ve tercüme kitap ile yüze yakın makale yazıp konferanslarda tebliğ sundu. Zaman zaman kendisini de eserlerine konu edindi, nitekim Soldat de Fortune isimli kitabı sıradan bir hatıradan çok muhtevası itibarıyla o döneme ait önemli bilgiler nakleden bir tarih kitabı özelliği taşımaktadır.

İkini Dünya Savaşı sırasındaki yaraları her ne kadar o dönemde iyileşse de yaşlandığında yeniden kendisine büyük acılar vermeye başlamış ve evinden çıkamaz olmuştu. Yine kendisi gibi ilerlemiş yaşına rağmen kaldığı manastırdan ziyaretine gelen kız kardeşi ile her türlü sağhlk ve diğer özel işleriyle ilgilenen yeğeni dışında herhangi bir ziyaretçisi kalmadı, zaten kendisi de ziyaretçi kabul edecek durumda değildi. Yaklaşık on yıldır yatağa mahkûm olmuş bir hayat süren Vincent Mansour Monteil 27 Şubat 2005 tarihinde vefat etti. 1995'te Jacques Berque'in ve 2004'te Maxime Rodinson'un ölmesinin ardından Fransızlar'ın eski kuşak şarkiyatçılarının hayatta kalan son ferdi Vincent Mansour Monteil'in de vefatıyla XX. yüzyıla damgasını vuran bu insanların dönemini kapatmış oldu.

Vincent Mansour Monteil'in başlıca kitapları şunlardır: Un écrivain persan du demi-siècle: Sâdeq Hedâyat (Téhéran 1903-Paris 1951)-Ifi, Editions de l'Institut Franco-iranien, Téhéran 1952; Annuaire du Monde Musulman, Presses Universitaires de France-PUF, Paris 1955; Le Persan contemporain. Textes et Vocabulaires, Librairie C. Klincksieck, Paris 1955, L'Iran, Editions 
du Seuil, Collection "Petite Planete", Paris 1957, 1967, 1978; Les Musulmans soviétiques, Edition du Seuil, Paris 1957; Les Arabes, P.U.F., 1957 (Coll. "Que sais-je?), Paris 1957, 1964; L'Arabe moderne, Librarie C. Klincksieck, Paris 1960; Le Maroc, Editions du Seuil (Coll. "Petite Planète"), Paris 1962; Le Monde musulman, Horizons de France, Paris 1963; Le Monde musulman, Horizons de France, Paris 1963, 1972; L'Islam, Bloud et Gay, Paris 1963; L'Islam noir, Editions du Seuil, Paris 1964; Soldat de fortune, Grasset, Paris 1966; Discours sur l'histoire universelle d'Ibn Khaldûn, UNESCO, Beyrouth 1967-68, (Sindbad, Paris 1978), Arles: Actes-Sud, Paris 1997; Voyages d'Ibn Battuta, Anthropos, Paris 1968; Indonésie, Horizons de France, Paris 1970; Clefs pour la pensée arabe, Editions Seghers, Paris 1977; Le Monde arabe. Tradition et renouveau, Editions des trois continents-Lausanne/Vilo-Paris, Lausanne 1977; Abû-Nuwâs. Le vin, le vent, la vie (Anthologie d'Abû-Nuwâs), Sindbad, Paris 1979; Dossier secret sur Israél: le terrorisme, Editions Guy Authier, Paris 1978; Quatrains d'Omar Khayyâm et Ballades de Hâfez, Arles: Actes-Sud/Sindbad, Paris 1983; L'Epitre du pardon, Gallimard, Paris 1984, (Meşhur Arap filozof ve şairi Ebu'l-Alâ el-Ma'arrînin (ö.449/ 1057) Risâletü'l-gufrân adl eserinin tercümesi); Aux cinq couleurs de l'Islam, Maisoneuve et Larose, Paris 1989; Lawrence d'Arabie: le lévrier fatal 1888-1935, Hachette 1987; L'amour, l'amant, l'aimé, Sindbad/Unesco, Paris 1989, (Akbar Tadjvidi ile birlikte Hâfı-ı Şîââinnin (ö.792/1390) Divân'ından seçme şiirlerinin tercümesi); Le livre de l'Inde: extraits chosis, Gallimard, Paris 1987, (Ebû Reyhân Muhammed El-Bîrûnî̀nin Tahkîk mâ li'l-Hind adlı eserinin tercümesi).

Makalelerinden bazıları ise şunlardır: "Essai sur l'Islam en URSS", Revue des Etudes Islamiques, 20, 1952, s.5-146; "Sur le dialecte turc de l'Azerbâdjân iranien", $J A, 244,1956$, s.1-77; "The evolution and setting of the nomads of the Sahara", Int. Soc. Sci. Bull., II, 1959, s.572-584; "Une confrérie musulmane: les Mourides du Sénégal”, Archives de sociologie des religions, 10, 1960, s.77-102; "La décolonisation de l'Histoire", Preuves, (Paris), n.142, déc. 1962, s.3-12; "Sur l'arabisation des langues négro-africaines", Génève-Afrique, Acta Africana, 2, 1963, s.12-19; "La religion des Black Muslims", Esprit, Octobre 1964, s. 601-629; "Les manuscrits historiques arabo-africains (Bilan provisoire)", Bull. IFAN, XXVII, 3-4, 1965, s.531542; "Ibn Khaldoûn, sociologue et historien (1332-1406)", Rev. Hist., 237, 1967, s.339-358; "Marabouts", Islam in Africa, ed.: James Kritzeck and William H. Lewis, New York 1969, s.87-109; "Ce que nous devons aux Arabes", France-Pays arabes, n.8, Janvier 1970, s.7-10; "The problem of modernisation of Arabic", Modernisation of Languages in Asia, ed. S. Takdir 
Alisjahbana, s.344-349; "Les Janissaires", L'Histoire, n.8, Janvier 1979, s. 22-30; "Ibn Sina and Avicennism", Cultures, 7 iv, 1980, s.180-199; "Le mois de Ramadân", L'Histoire, n.25, Juillet-Août 1980; "A la recherche d'Ibn Quzman", Rivages et déserts. Hommage à Jacques Berque, Sindbad, Paris 1988, s.52-62. 